\title{
Size and seasonal temperature in free-ranging Drosophila subobscura
}

\author{
J.S. Kari, Raymond B. Huey* \\ Department of Zoology, Box 351800, University of Washington, Seattle, WA 98105-1800, USA
}

Received 14 July 1999; accepted 3 August 1999

\begin{abstract}
Body size of diverse ectotherms is inversely related to developmental temperature in the laboratory. We monitored seasonal variation in wing length of two populations (Oregon, Washington) of $D$. subobscura, which was introduced in the Pacific Northwest in the late 1970s. Wing length varied seasonally and was shortest in summer. In Washington, however, wing length was longest in spring, not winter. Wing length was inversely and curvilinearly related to mean ambient temperature, as in a few previous studies of drosophilids. Mid-winter D. subobscura might not be the largest either because extremely low temperatures depress size or because flies collected in winter were in fact born the previous autumn, when developmental temperatures were more moderate. (C) 2000 Elsevier Science Ltd. All rights reserved.
\end{abstract}

Keywords: Drosophila subobscura; Drosophila melanogaster; Drosophila simulans; Temperature; Body size; Reaction norm

\section{Introduction}

Reaction norms (Schmalhausen, 1949) that map adult body size on developmental temperatures are remarkably consistent in shape for diverse ectotherms: specifically, adult body size of laboratory reared individuals is almost always inversely related to developmental temperature (Atkinson, 1994, 1996). Wing length of Drosophila subobscura exemplifies this pattern [Fig. 1(A), from Moreteau et al., 1997] see also (David et al., 1983; Economos and Lints, 1986; Starmer, 1989); and size is largest in flies that were raised at low - though not the lowest - temperatures. The near

\footnotetext{
* Corresponding author. Tel: +1-206-543-1505; fax: + 1206-543-3041.

E-mail address: hueyrb@zoology.washington.edu (R.B. Huey).
}

universality of the inverse relationship for size versus temperature has recently attracted considerable attention (e.g. Atkinson, 1994, 1996; Berrigan and Charnov, 1994; Partridge and French, 1996; van der Have and de Jong, 1996), and both adaptive and non-adaptive explanations of the pattern have been proposed (reviewed in Atkinson and Sibly, 1997).

If reaction norms in the laboratory for size vs temperature predict size-temperature relationships in nature, then the body size of ectotherms (at least, those with multiple generations per year) in nature should vary inversely with seasonal environmental temperature (Atkinson, 1996). Thus individuals emerging in cool seasons should generally be larger than conspecifics emerging in warmer seasons. Of course, many environmental factors (e.g. crowding, nutrition, parental thermoregulation) vary seasonally and also influence body size in nature (Atkinson, 1979; David et al., 1983; Jones et al., 1987; Thomas, 1993; Gibert et al., 
1998). Consequently, field patterns of body size for free-ranging flies may not match predictions based on laboratory studies (Thomas, 1993).

Here we address the question of whether wing size of Drosophila subobscura varies seasonally with tem- perature. A few previous studies of Drosophila spp generally support an inverse relationship between ambient temperature and body size in nature (Tantawy, 1964; Krimbas, 1967; Atkinson, 1979; Thomas, 1993; Junge-Berberovic, 1996), though influences of
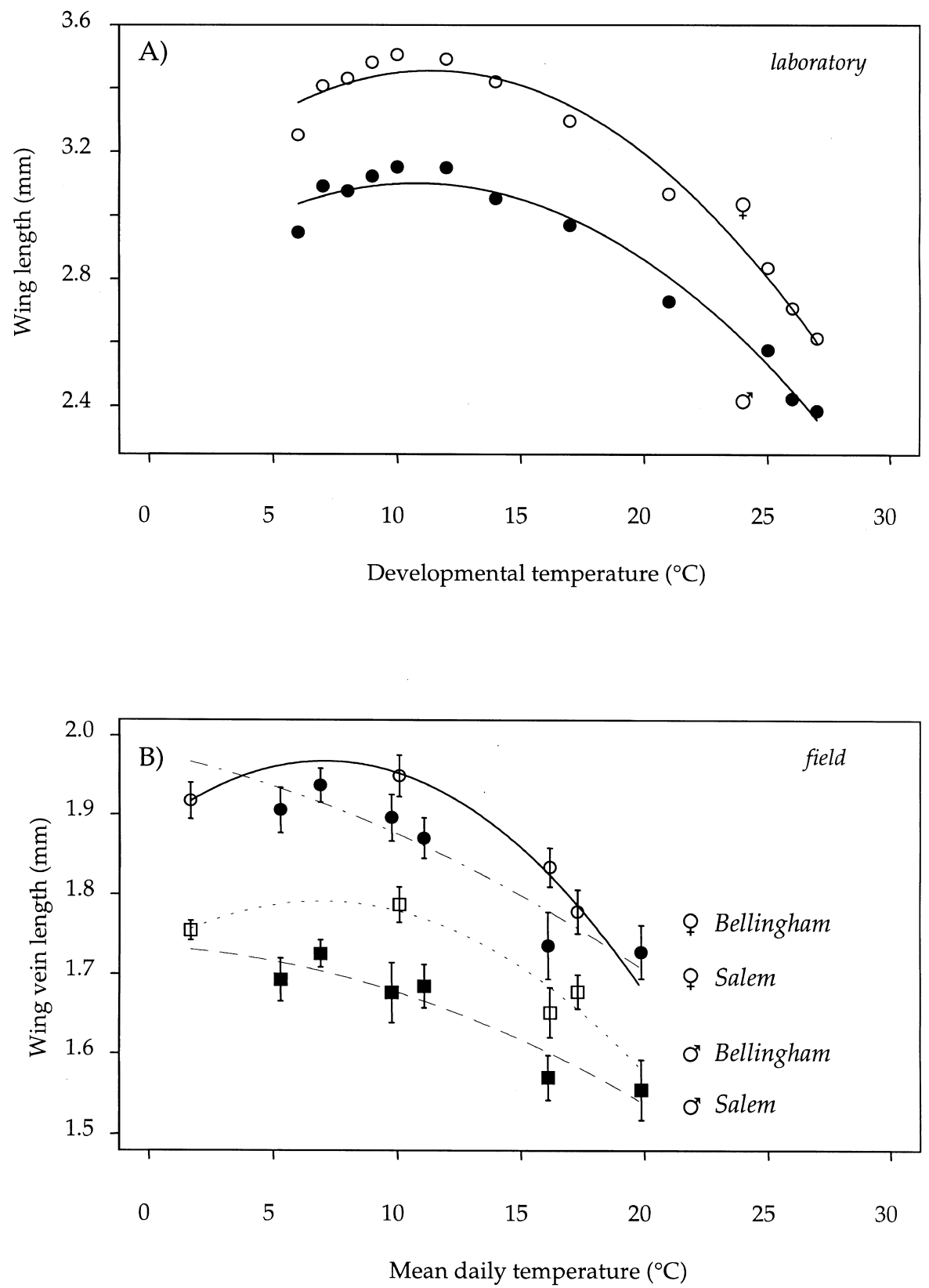

Fig. 1. (A) Mean wing length (mm) of female (open symbols) and of male (solid symbols) Drosophila subobscura that developed at different (constant) temperature (redrawn from Moreteau et al., 1997). Superimposed are second-order polynomial regressions. Note that these lengths are for the entire wing, not just the length of the L3 vein (as per Fig. 2, below). Data courtesy of B. Moreteau and J.R. David (personal communication). (B) Mean wing-vein length ( $\mathrm{mm} \pm 1 \mathrm{SE}$, length of L3) of female and of male $D$. subobscura from Bellingham (open symbols) and from Salem (sold symbols) versus mean daily temperature during the preceding month. Superimposed are second-order polynomial regressions, fitted separately for each locality and sex. 
density and nutrition on size are also indicated (Atkinson, 1979; Thomas, 1993).

We examined seasonal (summer through winter) variation in wing size in two populations (Bellingham, WA and Salem, OR) of D. subobscura from the Pacific Northwest and searched for patterns of co-variation in wing size with average ambient temperature. Wing size of D. subobscura is inversely related to temperature in the laboratory, except at extreme low temperature [Fig. 1(A), Moreteau et al., 1997]. Consequently, if environmental temperature is a key determinant of body size in nature, then flies captured in winter should be much larger than flies captured in the summer. Moreover, Washington flies (higher latitude, cooler temperature) should be larger than Oregon flies at the same season.

Drosophila subobscura, which is widely distributed in Europe, was accidentally introduced into both North and South America in the late 1970s (Brncic et al., 1981; Beckenbach and Prevosti, 1986). The invading flies spread rapidly on both continents, and populations within continents became genetically subdivided soon after the introductions (Ayala et al., 1989; Brncic, 1995). The invasions have been very successful. In fact, D. subobscura is often the most abundant Drosophila at high latitudes in the New World (Pascual et al., 1993; Brncic, 1995), where it is active throughout the year during good weather. Laboratory reaction norms for D. subobscura [Fig. 1(A), Moreteau et al., 1997] are known, but the seasonal variation in size for this species has been published only in Switzerland between May and September (Junge-Berberovic, 1996) and in Greece for spring through fall (Krimbas, 1967). In only two decades since the introduction, the North American populations have evolved a latitudinal cline in wing size that is remarkably similar to that of the native European populations (Huey et al., submitted).

\section{Materials and methods}

To analyze the body size of $D$. subobscura, we collected ten field samples [six from Salem, OR $\left(44^{\circ} 55^{\prime} \mathrm{N}\right)$ and four from Bellingham, WA $\left(48^{\circ} 46^{\prime} \mathrm{N}\right)$ ] at different times of the year between June 1995 and February 1997. (Note: flies were intentionally sampled over different years.) Baits (bananas with yeast) were placed in second growth forests in Salem (Bush's Pasture Park) and in Bellingham (Sehome Arboretum, Western Washington University). Flies were collected from 10 a.m. to dusk and later identified based on wing and sex-comb characteristics (Beckenbach and Prevosti, 1986). However, because wing traits (used to identify females) are not always diagnostic, we checked the male progeny of 20 females (tentatively identified as subobscura) from each locality. All were correctly identified. One wing from each of 20 males and 20 females from each field sample was mounted on a slide. A video camera attached to a photo-microscope and digitizer was used to view and measure the wings (lengths were calibrated against a micrometer). The length of the third longitudinal vein served as an index of wing size (Partridge et al., 1987). Seasonal size data (sexes averaged) on D. melanogaster and on D. simulans in Alexandria, Egypt were obtained from Tantawy (1964), which did not specify how wing length was measured. Laboratory reaction norms for an Old World population of D. subobscura are from Moreteau et al. (1997). These latter measurements are based on the full length of the wing (from insertion to tip), and are thus longer than those we took.

The actual developmental temperatures experienced by $D$. subobscura in nature in different seasons are unknown. However, we obtained an index of ambient
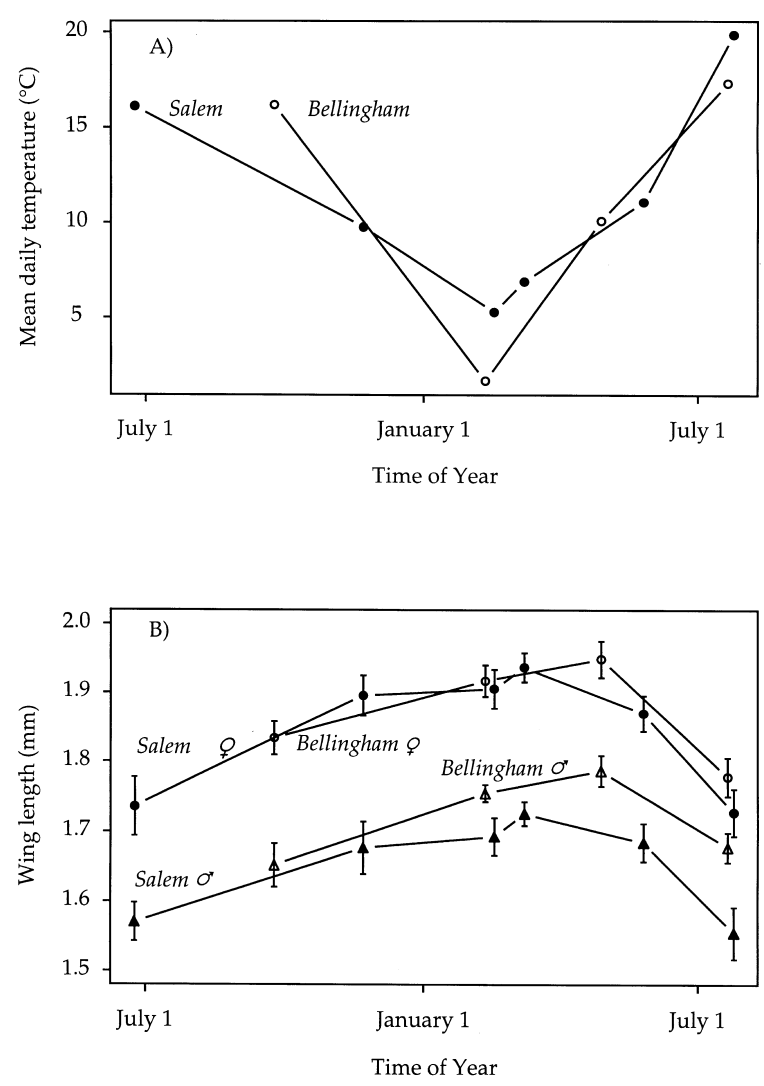

Fig. 2. (A) Mean daily temperature for Bellingham, WA (open symbols) and for Salem, OR (solid) at different times of year. Mean daily temperatures were averaged for the 30 days prior to each collection. (B) Mean wing length $(\mathrm{mm} \pm 1 \mathrm{SE}$, length of L3 vein, see Section 2) of female and of male $D$. subobscura from Bellingham (open) and from Salem (solid) at different times of year. 
temperatures preceding collections by examining weather records for Bellingham and Salem for the 30day period prior to each collection. We extracted daily mean temperatures from the NOAA weather database at the NCDC Global Summary of Day (http:// www.ncdc.noaa.gov/pub/data/globalsod/gsod.html $\sharp$ A) and then averaged for these 30-day periods. Temperature data from Tantawy (1964) were similarly based on mean daily temperatures for the month. To describe the relationship between wing size and temperature, we used a second-order (orthogonal) polynomial regression (Delpuech et al., 1995) with locality and sex as factors.

\section{Results}

Environmental temperatures show major seasonal shifts both in Bellingham and Salem [Fig. 2(A)]. Overall, Bellingham, which is further north, is cooler on average than Salem (multiple years, data not shown).

Wing lengths varied seasonally [Fig. 2(B)]. Flies at both sites were smallest in summer. Flies from Bellingham were largest in spring (late April); and from Salem were largest in winter (February, March), but unfortunately no late-April sample is available.

Wing length appeared to vary with mean daily temperatures for the previous month, sex, and locality [Fig. 1(B)]. To quantify these patterns, we ran a polynomial regression (Atkinson, 1979; Delpuech et al., 1995) with sex and locality as factors, and with temperature as a second-order polynomial (Table 1). None of the interactions was significant, so only the main effects were included in the final analysis. Females were much larger than males $(P<0.0001)$, and Bellingham flies were lager than Salem ones $(P<0.0001)$. The linear term for mean daily temperature was significant $(P<0.0001)$ and strongly negative. The quadratic term was also significant $(P<0.0001)$; however, the

Table 1

Analysis of variance for effects of sex, locality, and temperature (second-order polynomial) on log (wing length) of $D$. subobscura. Because none of the interactions was significant, only main effects are included in the analysis shown. The multiple $R^{2} 0.4626(P<0.0001)$

\begin{tabular}{lccl}
\hline Terms & Coefficient & $t$ value & $P$ \\
\hline (Intercept) & 0.568 & 159.049 & $<0.0001$ \\
Sex & -0.050 & -14.416 & $<0.0001$ \\
Locality & -0.017 & -4.60 & $<0.0001$ \\
$\begin{array}{l}\text { Temperature } \\
\quad \text { (linear) }\end{array}$ & -0.679 & -9.751 & $<0.0001$ \\
$\quad$ quadratic) & -0.324 & -4.599 & $<0.0001$ \\
\hline
\end{tabular}

field reaction norm for Bellingham was suggestive more curvilinear than that of Salem [Fig. 1(B)], probably reflecting the more extreme low temperatures at Bellingham during winter.

\section{Discussion}

Laboratory reaction norms for size as a function of developmental temperature [Fig. 1(A), Moreteau et al., 1997] suggest that body size in nature should vary seasonally and should be inversely proportional to the seasonal temperature. Moreover, if environmental temperatures reach sufficiently low levels [see Fig. 1(A)], the field reaction norm can potentially be curvilinear. In fact, body size in D. subobscura in the Pacific Northwest did vary seasonally [Fig. 2(B)] and was inversely and curvilinearly related to mean daily temperature for the preceding month [Fig. 1(B), Table 1]. Laboratory reaction norms and field seasonal patterns differ somewhat in position [cf. Fig. 1(A) vs 1(B)], but this may merely reflect the fact that mean daily temperatures will be rough indices of actual developmental temperatures (Jones et al., 1987).

Body size in Old World D. subobscura has never been measured over a full year. However, flies from Mt. Parnes, Greece are bigger in spring than in summer (Krimbas, 1967); and size in flies from Switzerland appears inversely related to ambient temperature between May and September (Junge-Berberovic, 1996).

Although size was inversely related to environmental temperature in our samples [Fig. 1(B)], flies from Bellingham were largest in spring [Fig. 2(B)], not in winter, when environmental temperatures were lowest [Fig. 2(A)]. We can offer three possible explanations. First, mid-winter samples at Bellingham might have developed at extreme low temperatures, which do produce relatively small $D$. subobscura in the laboratory (see Fig. 1, Moreteau et al., 1997). Second, flies collected in mid-winter might actually have developed the previous fall, when developmental temperature would have been much warmer. Interestingly, many of the $D$. subobscura captured in Northern England in mid winter appear to have eclosed the previous autumn (Begon, 1976); but whether this pattern holds in the Pacific Northwest remains to be determined. Third, another environmental factor (e.g. crowding, nutrition, photoperiod, thermoperiod) might have reduced body size in winter below that expected based on environmental temperature alone (David et al., 1980; Thomas, 1993; Tables 4 and 5 in Junge-Berberovic, 1996). Further investigations, including laboratory "common garden" ones (Begon, 1976; Thomas, 1993), will be necessary to account for the winter-spring patterns of wing size. 


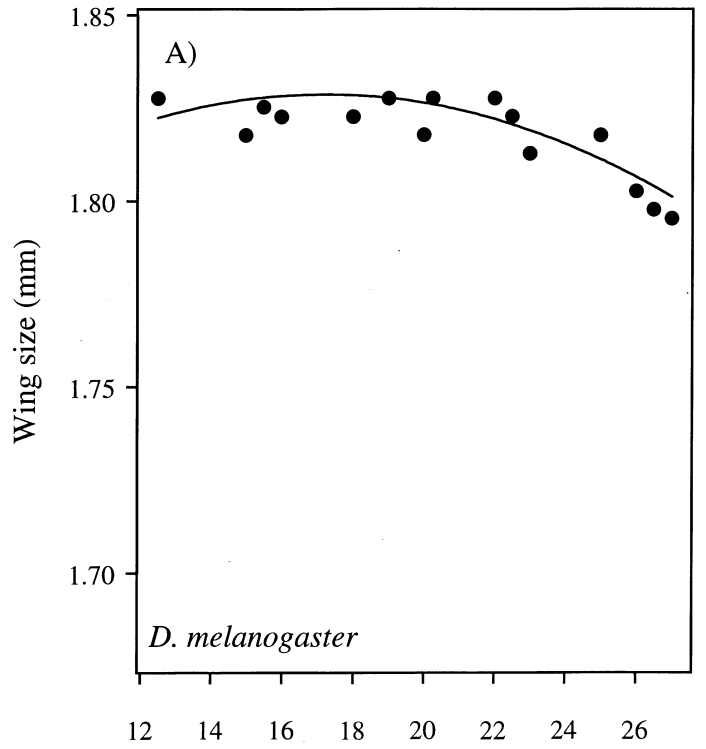

Mean daily temperature $\left({ }^{\circ} \mathrm{C}\right)$

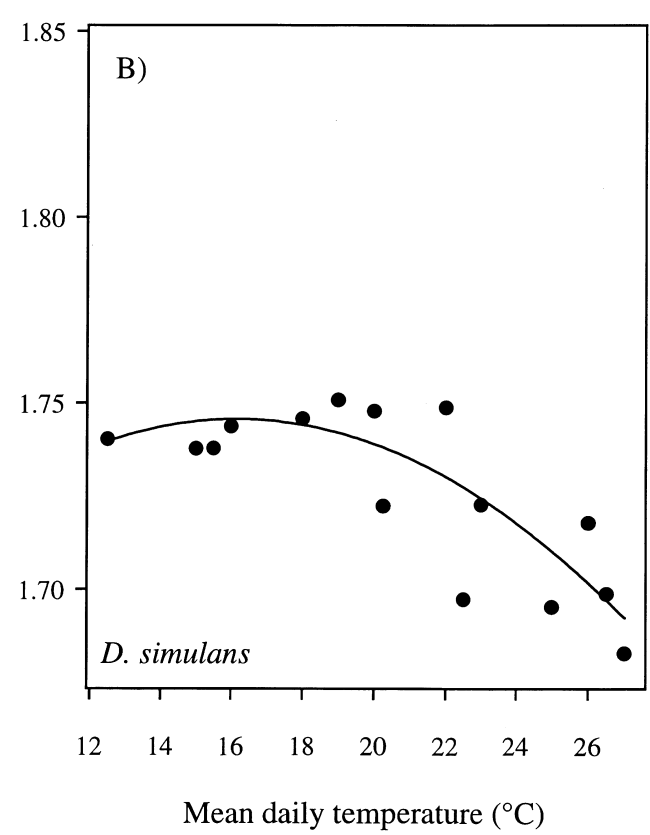

Mean daily temperature $\left({ }^{\circ} \mathrm{C}\right)$

Fig. 3. (A) Mean wing length (mm) of D. melanogaster and (B) of D. simulans (sexes averaged) from Egypt vs average environmental temperature during that month, with second-order polynomial regressions. Data compiled and regressions calculated from Figs. 1 and 3 in Tantawy (1964).

Our samples are taken directly from the field, and so we have necessarily assumed that the observed seasonal variation in size is driven largely by environmental variation. We cannot, of course, exclude the possibility that part of the variation reflects a genetic response to seasonal selection. However, field heritabilities for wing size are very low in D. subobscura (Orengo and Prevosti, 1999), such that any genetic contribution must be minor.

To determine whether the curvilinear relationship (size vs ambient temperature) for D. subobscura was unusual, we searched for previous studies of seasonal variation in wing size of Drosophila. Atkinson (1979) documented a significant curvilinear effect for free-ranging D. melanogaster from England $\left(53^{\circ} 48^{\prime}\right)$ between May and October. Tantawy (1964) published size and temperature data for free-ranging $D$. melanogaster and D. simulans from Alexandria, Egypt $\left(31^{\circ} 12^{\prime} \mathrm{N}\right)$ over the full year, and we used polynomial regressions (Delpuech et al., 1995) to reanalyze these data (Fig. 3). Linear and quadratic terms for temperature were significant $(P \mathrm{~s}<0.001)$ for both species. Thus, the curvilinear pattern we found for D. subobscura from the New World [Fig. 1(B)] may be widespread for temperate-zone Drosophila (Fig. 3; Atkinson, 1979); but clearly more studies are needed.

Bellingham flies were significantly larger than Salem flies, even when environmental temperatures is used as a covariate [Fig. 1(B), Table 1]. Whether nutritional or genetic differences are responsible will require further studies.

In conclusion, field collections D. subobscura demonstrate that wing size is inversely but curvilinearily related to mean daily temperature. As a result, flies collected in mid-winter are large, but not necessarily the largest flies. Significant curvilinear seasonal size patterns were also detected in re-analyses of published data for $D$. melanogaster and $D$. simulans from northern Egypt and have been previously reported for $D$. melanogaster in England. The causal mechanism underlying curvilinear field reaction norms needs investigation.

\section{Acknowledgements}

This project was funded by NSF grants (IBN 9514205) to RBH and DEB 9629822 to RBH and G. Gilchrist. We thank G. Gilchrist and A. Litt for assistance and J.R. David, D. Berrigan, P. Gibert, and G. Gilchrist for constructive discussion. We acknowledge B. Moreteau and J.R. David for generously providing access to data used in Fig. 1(A). 


\section{References}

Atkinson, D., 1994. Temperature and organism size - a biological law for ectotherms? Adv. Ecol. Res. 25, 1-58.

Atkinson, D. 1996. Ectotherm life-history responses to developmental temperature. In: Johnston, I.A., Bennett, A.F. (Eds.), Animals and Temperature: Phenotypic and Evolutionary Adaptation. Cambridge University Press, Cambridge, pp. 183-204.

Atkinson, D., Sibly, R.M., 1997. Why are organisms usually bigger in colder environments? Making sense of a life history puzzle. Tree $12,235-239$.

Atkinson, W.D., 1979. A field investigation of larval competition in domestic Drosophila. J. Anim. Ecol. 48, 91-102.

Ayala, F.J., Serra, L., Prevosti, A., 1989. A grand experiment in evolution: the Drosophila subobscura colonization of the Americas. Genome 31, 246-255.

Beckenbach, A.T., Prevosti, A., 1986. Colonization of North America by the European species Drosophila subobscura and D. ambigua. Am. Midl. Nat. 115, 10-18.

Begon, M., 1976. Temporal variations in the reproductive condition of Drosophila obscura Fallen and D. subobscura Collin. Oecologia 23, 31-47.

Berrigan, D., Charnov, E.L., 1994. Reaction norms for age and size at maturity in response to temperature: a puzzle for life historians. Oikos 70, 474-478.

Brncic, D. 1995. Colonization of Chile by Drosophila subobscura and its consequences. In: Levine, L. (Ed.), Genetics of Natural Populations: The Continuing Importance of Theodosius Dobzhansky. Columbia University Press, New York, pp. 154-169.

Brncic, D., Prevosti, A., Budnik, M., Monclús, M., Ocaña, J., 1981. Colonization of Drosophila subobscura in Chile I. First population and cytogenetic studies. Genetica 56, 3-9.

David, J.R., Allemand, R., Van Herrewege, J., Cohet, Y. 1983. Ecophysiology: abiotic factors. In: Ashburner, M., Carson, H.L., Thompson, J.N. (Eds.), The Genetics and Biology of Drosophila. Academic Press, London, pp. 106169.

Delpuech, J-M., Moreteau, B., Chiche, J., Pla, E., Vouidibio, J., David, J.R., 1995. Phenotypic plasticity and reaction norms in temperature and tropical populations of Drosophila melanogaster: ovarian size and developmental temperature. Evolution 49, 670-675.

Economos, A.C., Lints, F.A., 1986. Developmental temperature and life span in Drosophila melanogaster I. Constant developmental temperature: evidence for physiological adaptation in a wide temperature range. Gerontology 32, 1827.

Gibert, P., Moreteau, B., Moreteau, J-C., David, J.R., 1998. Genetic variability of quantitative traits in Drosophila mel- anogaster (fruit fly) natural populations: analysis of wildliving flies of several laboratory generations. Heredity 80 , 326-335.

Huey, R.B., Gilchrist, G.W., Carlson, M.L., Berrigan, D., Serra, L., Rapid evolution of a geographic size cline in an introduced fly, submitted.

Jones, J.S., Coyne, J.A., Partridge, L., 1987. Estimation of the thermal niche of Drosophila melanogaster using a temperature-sensitive mutant. Am. Nat. 130, 83-90.

Junge-Berberovic, R., 1996. Effect of thermal environment on life histories of free-living Drosophila melanogaster and $D$. subobscura. Oecologia 108, 262-272.

Krimbas, C.B., 1967. The genetics of Drosophila subobscura populations III. Inversion polymorphism and climatic factors. Molec. Gen. Genetics 99, 133-150.

Moreteau, B., Morin, J-P., Gibert, P., Petavy, G., Pla, E., David, J.R., 1997. Evolutionary changes of nonlinear reaction norms according to thermal adaptation: a comparison of two Drosophila species. C.R. Acad. Sci. Paris 320, 833841.

Orengo, D.J., Prevosti, A., 1999. Wing-size heritability in a natural population of Drosophila subobscura. Heredity 82, $100-106$.

Partridge, L., French, V. 1996. Thermal evolution of ectotherm body size: why get big in the cold? In: Johnston, I.A., Bennett, A.F. (Eds.), Animals and Temperature: Phenotypic and Evolutionary Adaptation. Cambridge University Press, Cambridge, pp. 265-392.

Partridge, L., Hoffmann, A., Jones, J.S., 1987. Male size and mating success in Drosophila melanogaster and D. pseudoobscura under field conditions. Anim. Behav. 35, 468476.

Pascual, M., Ayala, F.J., Prevosti, A., Serra, L., 1993. Colonization of North America by Drosophila subobscura. Ecological analysis of three communities of drosophilids in California. Z. Zool. Syst. Evolut.-forsch 31, 216-226.

Schmalhausen, I.I., 1949. Factors of Evolution: The Theory of Stabilizing Selection. Blakiston, Philadelphia, P.A., reprinted 1986 by University of Chicago Press.

Starmer, W.T., 1989. Causes of variation in wing loading among Drosophila species. Biol. J. Linn. Soc. 37, 247-261.

Tantawy, A.O., 1964. Studies on natural populations of Drosophila. III. Morphological and genetic differences of wing length in Drosophila melanogaster and D. simulans in relation to season. Evolution 18, 560-570.

Thomas, R.H., 1993. Ecology of body size in Drosophila buzzatii: untangling the effects of temperature and nutrition. Ecol. Entomol. 18, 84-90.

van der Have, T.M., de Jong, G., 1996. Adult size in ectotherms: temperature effects on growth and differentiation. J. Theor. Biol. 183, 329-340. 